\title{
SINTESIS, PEMURNIAN DAN KARAKTERISASI METIL ESTER SULFONAT (MES) SEBAGAI BAHAN INTI DETERJEN DARI MINYAK BIJI NYAMPLUNG (Calophyllum inophyllum $\mathrm{L}$ )
}

\section{SYNTHESIS, PURIFICATION AND CHARACTERIZATION METHYL ESTER SULPHONATE AS CORE MATERIAL DETERGENT FROM SEED OIL OF Calophyllum inophyllum $\mathrm{L}$}

\author{
M. Chasani *, V.H. Nursalim , S. Widyaningsih , I.N. Budiasih , dan W.A. Kurniawan \\ Prodi Kimia MIPA, Universitas Jenderal Soedirman \\ *email: moch.chasani@gmail.com
}

\begin{abstract}
ABSTRAK
Metil ester sulfonat (MES) adalah salah satu jenis surfaktan yang dapat disintesis dari bahan baku minyak biji nyamplung (Calophyllum inophyllum L) yang potensial sebagai pengganti surfaktan dari minyak bumi. Proses sulfonasi dalam pembentukan MES diduga menghasilkan produk samping berupa di-salt yang dapat mengganggu kinerja MES dan memiliki daya deterjensi 50\% lebih rendah dari MES. Oleh karena itu, perlu dilakukan proses pemurnian untuk mereduksi kandungan di-salt dalam produk MES sehingga dapat memperbaiki kinerjanya. Penelitian ini bertujuan untuk mengetahui perbedaan karakteristik MES tanpa pemurnian dan MES hasil pemurnian serta mengetahui kondisi pemurnian MES yang menghasilkan karakteristik terbaik. Proses pemurnian dilakukan dengan menambahkan metanol pada konsentrasi 10, 20,30, 40\% dan waktu reaksi 30, 60, 90,120 menit. Pengaruh konsentrasi metanol (K) dan waktu reaksi (t) dikaji dalam rancangan acak lengkap dengan dua faktor yaitu konsentrasi dan waktu reaksi yang dilanjutkan dengan uji lanjut Duncan's Multiple Range Test DMRT. Karakterisasi dilakukan terhadap MES tanpa pemurnian dan MES hasil pemurnian meliputi nilai $\mathrm{pH}$, stabilitas emulsi, stabilitas busa, dan daya deterjensi. MES tanpa pemurnian setelah netralisasi memiliki nilai pH 7,819, stabilitas emulsi 33,33\%, stabilitas busa $19,765 \%$ dan daya deterjensi 68,80\%. MES hasil pemurnian setelah netralisasi memiliki $\mathrm{pH} 7,795$, stabilitasemulsi 90,455\%, stabilitasbusa 15,00\%, dan daya deterjensi 85,15\%.
\end{abstract}

Kata kunci : Minyak biji nyamplung, Metil ester sulfonat, Proses pemurnian.

\begin{abstract}
Methyl ester sulphonate (MES) is one of surfactants that can be synthesized from Calophyllum inophyllum $\mathrm{L}$ hich has a potency to subtitute petroleum surfactants. Sulphonation process in the formation of MES guess had side product such as di-salt which can disrupt MES performance and has detergency 50\% lower than MES. Therefore, the purification process is needed to reduce di-salt and improve MES performance. The aims of this research are to determine differences of characteristics of unpurified MES and purified MES also determine the best conditions of MES purification.The purification was done by adding methanol with the variation concentration 10,20, 30, 40\%and reaction time 30, 60, 90, 120 minutes. The effect of methanol concentration $(\mathrm{K})$ and reaction time (t) were studied in a completely randomized design with two factors which are methanol concentration and reaction time, then followed up by DMRT. Characterization of
\end{abstract}


unpurified MES and purified MES were $\mathrm{pH}$ value, emulsion stability, foam stability, and detergency. The unpurified MES had $\mathrm{pH}$ value after neutralized 7.819, emulsion stability $33.33 \%$, foam stability $19.765 \%$ and detergency $68.80 \%$. The purified MES had $\mathrm{pH}$ value after neutralized in $\mathrm{pH}$ valueafter neutralized 7.795 , emulsion stability $90.455 \%$, foam stability $15.00 \%$, and detergency $85.15 \%$.

Keywords : Calophyllum inophyllum L, Methyl ester sulphonate, Purification.

\section{PENDAHULUAN}

Penggunaan deterjen sebagai pembersih peralatan rumah tangga maupun industri meningkat seiring dengan bertambahnya penduduk di dunia khususnya di Indonesia. Limbah buangan hasil cucian yang mengandung deterjen seringkali dibuang secara langsung ke perairan baik sungai maupun laut. Kadar deterjen yang tinggi dalam perairan dapat bersifat toksik bagi organisme perairan sehingga menimbulkan kerusakan ekosistem dan air tanah yang nantinya dapat berdampak pada kehidupan manusia (Lewis, 1991)

Kandungan deterjen yang utama adalah surfaktan. Surfaktan merupakan zat aktif permukaan (surface active agent) yang dapat menurunkan tegangan permukaan suatu media, karena mempunyai kemampuan untuk menggabungkan bagian antar fase yang berbeda seperti udara dan air ataupun fase yang mempunyai kepolaran yang berbeda seperti minyak dan air. Sifat ini disebabkan struktur ampifilik surfaktan yang memiliki gugus hidrofilik (polar) dan gugus hidrofobik (Mehlin, dkk., 2007).

Surfaktan umumnya diproduksi dari bahan baku minyak bumi (petroleum). Contohnya adalah surfaktan anionik seperti LAS (linier alkylbenzene sulphonate) dan ABS (alkylbenzene sulphonate). Surfaktan LAS yang sangat sering digunakan oleh masyarakat secara luas menimbulkan masalah yakni LAS dapat membentuk fenol yang bersifat toksik bagi biota perairan. Surfaktan
ABS juga memiliki dampak negatif terhadap lingkungan karena sulit terdegradasi secara alami oleh mikroorganisme (Utomo, 2010). Selain itu, bahan baku minyak bumi yang digunakan merupakan sumber daya alam yang tidak dapat diperbaharui sementara kebutuhan deterjen semakin meningkat. Data kebutuhan akan surfaktan di Indonesia sekitar 95.000 ton per tahun, sedangkan kapasitas produksi dalam negeri sekitar 55.000 ton per tahun dan 45.000 ton masih diimpor yang diproduksi dari petroleum yang tidak ramah lingkungan (Wuryaningsih, 2006). Oleh karena itu, diperlukan alternatif bahan baku terbarukan yang nantinya dapat memenuhi kebutuhan surfaktan, yakni dari minyak nabati.

Surfaktan minyak nabati memiliki keunggulan sifatnya yang lebih ramah lingkungan karena biodegradable, pembusaan yang rendah dan sifat deterjensi yang baik (Trimurti, et.al, 2009). Sumber bahan baku alami yang dapat digunakan untuk produksi surfaktan adalah minyak biji nyamplung yang sangat berpotensi sebagai bahan baku surfaktan. Bijinya yang sudah tua memiliki kandungan minyak mencapai 50-70\% (Haryani dan Hargono, 2010).

MES yang dihasilkan pada proses sulfonasi masih mengandung di-salt (disodium karboksi sulfonat). Di-salt dapat mengganggu bahkan menurunkan kinerja MES karena memiliki sifat yang tidak diinginkan yaitu tidak larut dalam air dan daya deterjensi yang lebih rendah 50\% dari MES (Adiandri, 2006). Di-salt yang ada dalam surfaktan MES yang 
dihasilkan pada proses sulfonasi dapat diminimalkan dengan proses pemurnian. Proses pemurnian MES dilakukan menggunakan metanol dengan berbagai variasi konsentrasi dan variasi waktu reaksi. Metanol digunakan untuk mengurangi pembentukan di-salt sehingga dapat meningkatkan terbentuknya surfaktan MES dengan karakteristik yang baik dan dapat diaplikasikan sebagai deterjen bubuk. Tujuan penelitian ini adalah mengetahui perbedaan karakteristik produk MES tanpa pemurnian dan hasil pemurnian serta mengetahui kondisi proses pemurnian pada waktu dan konsentrasi metanol yang menghasilkan MES dengan karakteristik paling baik.

\section{METODE PENELITIAN}

\section{Alat dan Bahan}

Peralatan yang digunakan adalah alat gelas, hot plate stirrer, thermometer, blender, timbangan analitik, rotary evaporator, refluks, $\mathrm{pH}$-meter, spektrofotometer UV-Vis dan spektrofotometer FT-IR (Laboratorium Kimia Organik FMIPA UGM). Bahanbahan yang digunakan adalah minyak biji nyamplung, $\mathrm{Na}_{2} \mathrm{SO}_{4}$ anhidrat, aquades, $\mathrm{HCl}, \mathrm{CH}_{3} \mathrm{OH}, \mathrm{KOH}, \mathrm{NaHSO}_{3}$, katalis $\mathrm{Al}_{2} \mathrm{O}_{3}$, timol biru $0,1 \%, \mathrm{NaOH}$, xylene, indikator fenolftalein, $n$-heksan, kain putih dan kertas saring.

\section{Prosedur Penelitian}

\section{Reaksi transesterifikasi}

Sebanyak 150 gram minyak biji nyamplung direaksikan dengan metanol (rasio mol 1:6) dan $\mathrm{KOH} \mathrm{1 \%} \mathrm{(b/b).} \mathrm{KOH}$ dilarutkan dalam metanol, kemudian dimasukkan ke dalam minyak. Campuran direfluks pada suhu $60{ }^{\circ} \mathrm{C}$ selama 6 jam. Campuran didinginkan kemudian dicampur dengan $35 \mathrm{~mL}$ aquades. Ester ditambahkan $\mathrm{Na}_{2} \mathrm{SO}_{4}$ anhidrat dan disaring.

\section{Analisis metil ester}

\section{Penentuan bilangan asam}

Sebanyak 1 gram metil ester ditimbang dan ditambahkan dengan 5 $\mathrm{mL}$ metanol netral $96 \%$ kemudian dipanaskan selama 10 menit dengan penangas air sambil diaduk. Larutan ini kemudian dititrasi dengan $\mathrm{KOH} 0,1 \mathrm{~N}$ menggunakan indikator fenolftalein sebanyak 1-3 tetes, sampai tepat terlihat warna merah jambu.

\section{Penentuan bilangan penyabunan}

Sampel metil ester sebanyak 1 gram dan ditambah larutan $\mathrm{KOH}$ alkoholis sebanyak $10 \mathrm{~mL}$ kemudian direfluks. Setelah itu ditambahkan 1-3 tetes larutan indikator fenolftalein dan dititrasi dengan $\mathrm{HCl}$ 0,5 $\mathrm{N}(\mathrm{mL})$.

\section{Penetapan bilangan ester}

Penetapan bilangan ester dihitung sebagai selisih antara bilangan penyabunan dan bilangan asam.

\section{Reaksi sulfonasi}

Sebanyak 50 gram metil ester minyak biji nyamplung direaksikan selama 4,5 jam dengan $\mathrm{NaHSO}_{3}$ (rasio mol 1:1,5) dan katalis $\mathrm{Al}_{2} \mathrm{O}_{3}$ 1,5\% (b/b) pada suhu $90{ }^{\circ} \mathrm{C}$ sampai $100{ }^{\circ} \mathrm{C}$ dengan kecepatan pengadukan $500 \mathrm{rpm}$.

\section{Uji surfaktan anionik}

Sebanyak 1-3 tetes timol biru 0,1\% ditambahkan ke dalam $1 \mathrm{~mL} \mathrm{HCl} \mathrm{0,005}$ $\mathrm{N}$. Larutan tersebut kemudian dimasukkan ke dalam $1 \mathrm{~mL}$ larutan yang akan diuji (surfaktan). Hasil positif adanya surfaktan anionik dalam larutan diindikasikan dengan terbentuknya warna ungu-kemerahan.

\section{Proses pemurnian MES}

Sebanyak $5 \mathrm{~mL}$ MES ditambahkan metanol dengan beberapa konsentrasi yaitu konsentrasi 10, 20, 30 dan 40\% direaksikan pada suhu $60{ }^{\circ} \mathrm{C}$ dan pengadukan $200 \mathrm{rpm}$ dengan variasi 
waktu 30, 60, 90, dan 120 menit. Campuran selanjutnya didiamkan selama 30 menit kemudian dilakukan netralisasi dengan penambahan $\mathrm{NaOH} 20 \%$ pada suhu $50-55{ }^{\circ} \mathrm{C}$ selama 30 menit dengan stirrer.

\section{Analisis spektroskopi FT-IR}

Sampel minyak biji nyamplung, metil ester hasil transesterifikasi, metil ester sulfonat (MES) tanpa pemurnian dan hasil pemurnian dianalisis dengan spektrofotometer FT-IR (Shimadzu FTIR-8201 PC) di Laboratorium Kimia Organik FMIPA UGM.

\section{Karakterisasi MES (surfaktan)}

MES tanpa pemurnian dan hasil pemurnian dikarakterisasi meliputi $\mathrm{pH}$, stabilitas emulsi, stabilitas busa, dan daya deterjensi, masing-masing dua kali pengulangan. Karakteristik MES terbaik diperoleh dari nilai efektifitas MES hasil pemurnian.

\section{HASIL DAN PEMBAHASAN}

\section{Reaksi Transesterifikasi}

Hasil reaksi transesterifikasi berupa cairan berwarna kuning yang mengandung metil ester dan gliserol. Pemisahan metil ester dan gliserol dilakukan dengan menambahkan pelarut akuades dengan metode ekstraksi caircair menggunakan corong pisah (Sudarmadji, dkk., 1984). Hasilnya terbentuk 2 lapisan, yaitu lapisan atas berwarna kuning yang merupakan metil ester dan lapisan bawah berwarna putih yang merupakan gliserol, sisa metanol, sisa $\mathrm{KOH}$, dan akuades. Terbentuknya lapisan terjadi karena perbedaan kepolaran antara metil ester yang bersifat nonpolar dengan gliserol yang bersifat polar. Produk metil ester yang diperoleh kemudian ditambahkan $\mathrm{Na}_{2} \mathrm{SO}_{4}$ anhidrat dan disaring. Metil ester berwarna kuning bening dengan rendemen sebesar $63,98 \%$ (b/b) dari hasil transesterifikasi sebanyak 900,23 gram minyak nyamplung dihasilkan sebanyak 575,95 gram metil ester.

\section{Hasil Analisis Metil Ester}

\section{Nilai bilangan asam}

Bilangan asam merupakan jumlah mg $\mathrm{KOH}$ yang diperlukan untuk menetralkan asam lemak bebas yang terdapat dalam satu gram minyak atau lemak (Setyadi dan Susianti, 2003). Semakin banyak $\mathrm{KOH}$ yang digunakan untuk menetralkan asam lemak bebas dalam minyak menunjukkan bahwa semakin besar bilangan asam. Semakin besar bilangan asam menunjukkan bahwa semakin banyak asam lemak bebas yang terdapat di dalam minyak. Hasil analisis bilangan asam minyak nyamplung sebesar 53,405 $\mathrm{mg}$ $\mathrm{KOH} / \mathrm{gram}$. Hasil analisis bilangan asam metil ester sebesar 45,97 mg KOH/gram. Berdasarkan hasil yang diperoleh menunjukkan bahwa nilai bilangan asam metil ester lebih kecil dibandingkan nilai bilangan asam minyak biji nyamplung. Hal ini menunjukkan bahwa sebagian besar asam lemak dari minyak biji nyamplung telah terkonversi menjadi metil ester pada proses transesterifikasi.

\section{Nilai bilangan penyabunan}

Bilangan penyabunan merupakan banyaknya mg $\mathrm{KOH}$ yang dibutuhkan untuk menyabunkan satu gram lemak atau minyak (Setyadi dan Susianti, 2003). Jumlah $\mathrm{KOH}$ yang diperlukan untuk menyabunkan molekul berdasarkan panjang rantai karbon asam lemak yang terkandung pada trigliserida dan bobot molekul trigliserida. Hasil analisis bilangan penyabunan minyak biji nyamplung sebesar 97,605 $\mathrm{mg}$ $\mathrm{KOH} /$ gram. Hasil analisis bilangan penyabunan metil sebesar 99,32 $\mathrm{mg}$ $\mathrm{KOH} /$ gram. Berdasarkan hasil yang diperoleh menunjukkan bahwa sejumlah trigliserida dan asam lemak bebas pada minyak biji nyamplung dan metil ester 
telah tersabunkan oleh $\mathrm{KOH}$ berlebih dalam pelarut alkohol. Sabun yang terbentuk merupakan garam alkali karboksilat yang berasal dari rantai asam lemak dan gliserida yang terkandung di dalam minyak biji nyamplung maupun metil ester. Semakin banyak sabun yang terbentuk menunjukkan bahwa semakin kecil bobot molekul dari asam lemak dan gliserida yang terkandung di dalam minyak biji nyamplung dan metil ester.

\section{Nilai bilangan ester}

Bilangan ester menunjukkan jumlah asam organik yang bersenyawa sebagai ester (Setyadi dan Susianti, 2003). Bilangan ester minyak biji nyamplung berasal dari senyawa ester yang berupa trigliserida yang terkandung di dalamnya. Nilai bilangan ester minyak biji nyamplung sebesar 44,20 $\mathrm{mg}$ $\mathrm{KOH} /$ gram sedangkan nilai bilangan ester metil ester sebesar 53,35 mg $\mathrm{KOH} /$ gram. Berdasarkan hasil yang diperoleh menunjukkan bahwa nilai bilangan ester dari metil ester minyak nyamplung lebih besar dibandingkan dengan nilai bilangan ester minyak biji nyamplung. Hal ini menunjukkan bahwa sejumlah asam lemak bebas yang terkandung di dalam minyak biji nyamplung ikut bereaksi saat proses transesterifikasi menjadi senyawa metil ester sehingga bilangan ester metil ester lebih besar dari bilangan ester minyak biji nyamplung.

\section{Hasil Sulfonasi}

Produk metil ester sulfonat (MES) dapat dihasilkan dari proses sulfonasi dengan mereaksikan metil ester dan $\mathrm{NaHSO}_{3}$. Penggunaan natrium bisulfit $\left(\mathrm{NaHSO}_{3}\right)$ berlebih bertujuan untuk memaksimalkan terbentuknya gugus sulfonat pada metil ester. Reaksi sulfonasi berlangsung cukup lama sehingga menggunakan katalis aluminium oksida $\left(\mathrm{Al}_{2} \mathrm{O}_{3}\right) \quad 1,5 \% \quad(\mathrm{~b} / \mathrm{b})$ untuk mempercepat reaksi. Reaksi sulfonasi antara metil ester dengan $\mathrm{NaHSO}_{3}$ terjadi pada bagian $\alpha$-atom karbon atau pada bagian rantai tidak jenuh (ikatan rangkap) (Adiandri, 2006). MES yang terbentuk dari hasil sulfonasi berwarna hijau yang merupakan MES kasar yang diduga masih mengandung di-salt (disodium karboksi sulfonat) sebagai hasil samping reaksi sulfonasi. Rendemen MES yang diperoleh dari hasil penelitian adalah $89,40 \%$ (b/b) yaitu dari metil ester sebanyak 300 gram dihasilkan sebanyak 268,2 gram MES kasar.

\section{Hasil Uji Surfaktan Anionik}

Keberadaan surfaktan anionik dapat diketahui dengan melakukan pengujian fisik menggunakan metode pengujian timol biru dengan $\mathrm{HCl}$ dan timol biru sebagai indikator. MES hasil penelitian menunjukkan hasil positif terhadap uji timol biru yang ditandai dengan terbentuknya warna ungu kemerahan pada larutan MES yang diuji. Hal ini menunjukkan bahwa MES yang dihasilkan pada penelitian merupakan surfaktan anionik. Warna ungu kemerahan pada larutan menunjukkan keberadaan gugus sulfonat $\left(-\mathrm{SO}_{3} \mathrm{H}\right)$ yang merupakan anion yang akan terikat pada karbon karbonil timol biru (Ardiyanto, 2012).

\section{Hasil Pemurnian MES}

Hasil reaksi sulfonasi berupa metil ester sulfonat (MES) kasar yang diduga masih mengandung di-salt (disodium karboksi sulfonat) yang merupakan hasil samping reaksi sulfonasi. Molekul $d i$ salt mengandung 2 kation $\mathrm{Na}^{+}$pada gugus esternya. Di-salt merupakan surfaktan yang memiliki daya deterjensi yang rendah dan cenderung menurunkan kinerja MES sehingga keberadaan di-salt tidak diinginkan. Kandungan di-salt dalam MES dapat dikurangi dengan melakukan pemurnian terhadap MES hasil sulfonasi. 
Proses pembentukan MES dan disalt terjadi melalui senyawa intermediet. Intermediet II di dalam reaksi diduga berupa senyawa metil ester yang mengikat gugus $\mathrm{HSO}_{3}$ pada bagian atom $\mathrm{C}$ karbonilnya. Intermediet II kemudian bereaksi dengan $\mathrm{HSO}_{3}{ }^{-}$berlebih menghasilkan intermediet III. Intermediet III diduga berupa senyawa metil ester sulfonat yang mengikat gugus $\mathrm{HSO}_{3}$ pada bagian atom $\mathrm{C}$ karbonilnya. Sebelum dilakukan netralisasi, MES hasil sulfonasi akan bereaksi dengan metanol. Hal ini bertujuan untuk mencegah terbentuknya di-salt. Metanol diduga akan bereaksi dengan intermediet III membentuk MESA (methyl ester sulphonic acid) dan $\mathrm{CH}_{3} \mathrm{HSO}_{4}$. Penambahan metanol dapat membuat terjadinya persaingan reaksi antara $\mathrm{CH}_{3} \mathrm{OH}$ dengan $\mathrm{HSO}_{3}$ yang terdapat pada intermediet III sehingga $\mathrm{CH}_{3} \mathrm{OH}$ bereaksi dengan $\mathrm{HSO}_{3}$ membentuk $\mathrm{CH}_{3} \mathrm{HSO}_{4}$. Hal ini akan mencegah terjadinya pembentukan di-salt karena hasil reaksinya berupa MESA akan langsung bereaksi dengan $\mathrm{NaOH}$ membentuk metil ester sulfonat (MES).

Proses netralisasi bertujuan untuk mencegah $\mathrm{pH}$ MES terlalu rendah (bersifat asam) dan mencegah terjadinya hidrolisis yang dapat menyebabkan pembentukan di-salt (Yuninda, 2009). MES hasil pemurnian sebelum netralisasi masih dalam bentuk MESA. MESA setelah proses netralisasi akan berubah menjadi MES yang mengikat satu kation $\mathrm{Na}^{+}$yang merupakan garam yang nantinya akan terdisosiasi dalam air sehingga MES akan berada dalam bentuk aktifnya yaitu bermuatan negatif (surfaktan anionik).

\section{Hasil Analisis dengan FT-IR}

Hasil spektrum FT-IR spektrum FTIR untuk minyak biji nyamplung teridentifikasi adanya serapan di daerah $3471,87 \mathrm{~cm}^{-1}$ menunjukkan adanya gugus hidroksil $(-\mathrm{OH})$. Adanya pita serapan pada daerah 2924,09 $\mathrm{cm}^{-1}$ menunjukkan vibrasi regangan untuk ikatan $\mathrm{C}_{\mathrm{sp} 3}-\mathrm{H}$. Pita serapan di daerah $1743,65 \mathrm{~cm}^{-1}$ dan $1712,79 \mathrm{~cm}^{-1}$ menunjukkan adanya vibrasi regangan gugus karbonil $(\mathrm{C}=\mathrm{O})$. Posisi serapan gugus $\mathrm{C}=\mathrm{O}$ pada daerah $1743,65 \mathrm{~cm}^{-1}$ menunjukkan adanya gugus karbonil pada ester yang berada di daerah 1750$1735 \mathrm{~cm}^{-1}$ [12]. Terdapat pita serapan di daerah $1234,44 \mathrm{~cm}^{-1}$ dan $1165 \mathrm{~cm}^{-1}$ yang menunjukkan adanya ikatan $\mathrm{C}-\mathrm{O}$ ester minyak biji nyamplung yang berupa senyawa trigliserida. Posisi serapan gugus $\mathrm{C}=\mathrm{O}$ pada daerah $1712,79 \mathrm{~cm}^{-1}$ menunjukkan adanya gugus karbonil pada asam karboksilat tidak jenuh yang berada di daerah 1715-1680 $\mathrm{cm}^{-1}$ (Field, dkk., 2007). Senyawa ini berupa asam lemak bebas tidak jenuh yang ada di dalam minyak biji nyamplung. Pita serapan di daerah 1627,92 $\mathrm{cm}^{-1}$ menunjukkan adanya vibrasi regangan dari ikatan $\mathrm{C}=\mathrm{C}$. Hal ini menunjukkan adanya gliserida yang tidak jenuh. Rentang vibrasi gugus (-OH) di daerah $3600-3300 \mathrm{~cm}^{-1}$, vibrasi gugus $\mathrm{C}_{\mathrm{sp} 3}-\mathrm{H}$ di daerah 3000-2800 $\mathrm{cm}^{-1}$, vibrasi gugus $\mathrm{C}=\mathrm{C}$ di daerah 1660-1600 $\mathrm{cm}^{-1}$, dan vibrasi gugus C-O di daerah 1300-1000 $\mathrm{cm}^{-1}$ (Sastrohamidjojo, 1992).

Hasil spektrum FT-IR antara metil ester sulfonat dan minyak biji nyamplung menunjukkan daerah puncak-puncak serapan yang hampir sama. Perbedaan serapan terletak di daerah $1712,79 \mathrm{~cm}^{-1}$ yang tidak muncul pada pita serapan metil ester. Hal ini menunjukkan bahwa asam lemak bebas yang terdapat dalam minyak nyamplung sudah terkonversi menjadi metil ester sebagai hasil reaksi transesterifikasi.

Spektrum FT-IR MES tanpa pemurnian menunjukkan puncak-puncak yang mirip dengan puncak-puncak serapan pada metil ester. Perbedaan serapan terletak di daerah $1566,20 \mathrm{~cm}^{-1}$ yang muncul pada spektrum metil ester. 
Pita serapan di daerah 1566,20 $\mathrm{cm}^{-1}$ menunjukkan adanya ion karboksilat berupa garam karboksilat, yang diduga berasal dari di-salt yang terdapat dalam MES kasar. Pita serapan ion karboksilat berada di daerah 1600-1560 $\mathrm{cm}^{-1}$ (Silverstein, dkk., 1981). Adanya pergeseran pita serapan dari $1612,49 \mathrm{~cm}^{-}$ 1 menjadi $1604,77 \mathrm{~cm}^{-1}$ terjadi karena adanya ikatan gugus sulfonat $\left(-\mathrm{SO}_{3}\right)$ dengan $\mathrm{C} \alpha$ pada rantai hidrokarbon metil ester.

Spektrum FT-IR MES hasil pemurnian menunjukkan puncak-puncak yang mirip dengan puncak-puncak yang muncul pada spektrum MES tanpa pemurnian. Perbedaan serapan terletak di daerah $1566,20 \mathrm{~cm}^{-1}$ yang tidak muncul di spektrum MES hasil pemurnian. Hal ini menunjukkan bahwa pada MES hasil pemurnian diduga kandungan di-salt semakin menurun.

\section{Penentuan Perlakuan Terbaik MES Hasil Pemurnian}

Penentuan perlakuan terbaik proses pemurnian MES berdasarkan hasil pengujian beberapa karakteristik MES seperti daya deterjensi, stabilitas emulsi, dan stabilitas busa. Nilai $\mathrm{pH}$ tidak dijadikan ukuran untuk menentukan perlakuan terbaik karena nilai $\mathrm{pH}$ hanya digunakan untuk mengetahui apakah MES sudah netral atau belum. Kondisi $\mathrm{pH}$ MES yang netral sangat penting untuk diketahui karena nilai $\mathrm{pH}$ yang terlalu ekstrim dapat mengakibatkan hidrolisis MES yang dapat membentuk di-salt dan metanol.

Penentuan perlakuan terbaik dilakukan berdasarkan nilai efektifitas dari masing-masing karakteristik MES dengan menggunakan sistem bobot nilai. Bobot nilai tertinggi diberikan terhadap daya deterjensi dan stabilitas emulsi. Hal ini dilakukan karena daya deterjensi dan stabilitas emulsi merupakan karakter utama yang harus dimiliki surfaktan
MES dalam proses pembersihan kotoran yang nantinya digunakan sebagai bahan inti deterjen bubuk. Bobot nilai menengah diberikan terhadap stabilitas busa karena pengaruhnya terhadap kinerja MES kecil tetapi keberadaan busa dapat membantu proses pembersihan kotoran pada kain.

Hasil pemurnian MES dengan perlakuan terbaik yaitu pada penambahan konsentrasi metanol 20\% (K2) dan waktu reaksi selama 90 menit (t3) dengan nilai total efektifitas sebesar 0,83 . Hasil karakterisasi MES pada perlakuan terbaik (K2t3) untuk daya deterjensi sebesar $85,150 \%$, stabilitas emulsi sebesar $90,455 \%$, dan stabilitas busa sebesar $15 \%$.

\section{Perbandingan Karakteristik}

\section{Nilai pH}

Pengukuran nilai $\mathrm{pH}$ dilakukan terhadap MES kasar dan MES hasil pemurnian perlakuan terbaik (K2t3). Nilai $\mathrm{pH}$ sebelum netralisasi dari MES kasar diperoleh sebesar 4,469 sedangkan pH MES hasil pemurnian (K2t3) sebesar 3,094. MES kasar dan MES hasil pemurnian (K2t3) sebelum netralisasi berada pada kondisi asam. Hal ini terjadi karena diduga MES masih dalam bentuk MESA (methyl ester sulphonic acid) dan senyawa inetermediet III. Nilai $\mathrm{pH}$ dari MES hasil pemurnian (K2t3) sebelum netralisasi lebih rendah dibandingkan nilai pH MES kasar. Hal ini disebabkan karena adanya proses pemurnian membuat jumlah MESA yang terbentuk semakin banyak. Senyawa intermediet III yang direaksikan dengan metanol saat proses pemurnian menghasilkan MESA sehingga jumlah MESA semakin banyak. Oleh karena itu, $\mathrm{pH}$ MES hasil pemurnian (K2t3) sebelum netralisasi lebih bersifat asam dibandingkan MES kasar. Nilai pH MES kasar lebih tinggi dikarenakan MES tidak melalui proses 
pemurnian sehingga masih dalam bentuk MESA dengan jumlah yang sedikit dan senyawa intermediet III tidak bereaksi dengan metanol sehingga MESA tidak dapat terbentuk.

Nilai pH MES kasar setelah netralisasi sebesar 7,819 sedangkan $\mathrm{pH}$ MES hasil pemurnian (K2t3) sebesar 7,795. Proses netralisasi dilakukan untuk membuat suasana asam pada MES menjadi netral. Nilai pH MES hasil netralisasi yang mendekati nilai $\mathrm{pH} 7$ semakin baik karena $\mathrm{pH}$ yang dimiliki semakin netral menandakan MES tidak mendekati $\mathrm{pH}$ ekstrim (sangat basa) yang dapat mengakibatkan hidrolisis MES menjadi di-salt.

\section{Nilai stabilitas emulsi}

Pengujian kestabilan emulsi dilakukan terhadap MES kasar dan MES hasil pemurnian (K2t3). Nilai stabilitas emulsi untuk MES kasar sebesar 33,33\% sedangkan MES hasil pemurnian sebesar 90,455\%. Nilai stabilitas emulsi MES hasil pemurnian (K2t3) lebih besar dibandingkan dengan MES kasar. MES mampu mempertahankan kestabilan emulsi karena adanya pengaruh gugus hidrofilik dan hidrofobik yang dimiliki. Proses pemurnian diduga dapat membentuk MES dengan jumlah yang lebih banyak. Semakin banyak MES yang terbentuk semakin tinggi kemampuan dalam mempertahankan kestabilan emulsi. Molekul MES mengandung gugus hidrofilik berupa $\mathrm{SO}_{3}{ }^{-}$yang dapat mengikat air sedangkan gugus hidrofobiknya berupa rantai karbon dari asam lemak minyak biji nyamplung dapat mengikat xylene. Semakin banyak MES yang terbentuk semakin banyak pula air dan xylene yang diikat oleh MES. Kemampuan MES yang dapat mengikat air dan xylene mengakibatkan tegangan antarmuka yang terjadi antara air dan xylene semakin kecil. Turunnya tegangan antarmuka antara air dan xylene menandakan bahwa gaya tolak-menolak antara air dan xylene juga menurun. Hal ini mengakibatkan sistem emulsi yang terbentuk dengan adanya MES hasil pemurnian akan semakin stabil sehingga stabilitas emulsinya semakin tinggi.

\section{Nilai stabilitas busa}

Pengujian kestabilan busa dilakukan terhadap MES kasar dan MES hasil pemurnian (K2t3). Nilai stabilitas busa untuk MES kasar sebesar 19,765\% sedangkan MES hasil pemurnian sebesar $15 \%$. Nilai stabilitas busa MES hasil pemurnian (K2t3) lebih kecil dibandingkan dengan MES kasar. Hal ini terjadi karena kerapatan muatan negatif diantara molekul-molekul surfaktan MES kasar lebih tinggi dibandingkan dengan MES hasil pemurnian (K2t3). Kerapatan muatan surfaktan membantu terbentuknya gaya tolak-menolak diantara lapisan busa sehingga proses penyatuan antar busa semakin diperkecil. Kerapatan muatan yang tinggi pada lapisan antarmuka busa mampu meningkatkan stabilitas busa (Adiandri, 2006). Busa dari MES minyak biji nyamplung diharapkan mudah diuraikan oleh bakteri pengurai (biodegradable) secara alami agar tidak merusak ekosistem sehingga MES harus memiliki tingkat stabilitas busa yang sedang.

\section{Nilai daya deterjensi}

Pengujian daya deterjensi dilakukan terhadap MES kasar dan MES hasil pemurnian (K2t3). Nilai daya deterjensi untuk MES kasar sebesar $68,80 \%$ sedangkan MES hasil pemurnian sebesar $85,15 \%$. Nilai daya deterjensi MES hasil pemurnian (K2t3) lebih besar dibandingkan dengan MES kasar. MES hasil pemurnian (K2t3) memiliki daya deterjensi yang lebih besar diduga karena dengan adanya proses pemurnian mampu mencegah terbentuknya di-salt. Keberadaan di-salt yang dapat dicegah menyebabkan MES yang terbentuk 
semakin banyak sehingga MES memiliki kinerja yang maksimal dalam membentuk CMC (Critical Micelle Concentration) yang dapat mengangkat kotoran dari kain. Rendahnya daya deterjensi MES kasar diduga karena adanya kandungan di-salt yang terkandung dalam MES kasar. Di-salt memiliki daya deterjensi yang lebih rendah dari MES sekitar 50\% sehingga keberadaan di-salt mengganggu kinerja MES sebagai surfaktan untuk mengangkat kotoran pada kain (Adiandri, 2006).

\section{KESIMPULAN}

Kondisi proses pemurnian MES yang menghasilkan karakteristik terbaik K2t3 dengan karakteristik nilai $\mathrm{pH}$ setelah netralisasi sebesar 7,795, stabilitas emulsi sebesar 90,455\%, stabilitas busa sebesar $15,00 \%$ dan daya deterjensi sebesar $85,15 \%$. MES tanpa pemurnian memiliki karakteristik nilai $\mathrm{pH}$ setelah netralisasi sebesar 7,819, stabilitas emulsi sebesar 90,330\%, stabilitas busa sebesar $19,765 \%$ dan daya deterjensi sebesar 68,80\%, menunjukkan bahwa MES hasil pemurnian (K2t3) memiliki karakteristik yang lebih baik dibandingkan dengan MES kasar yang nantinya diaplikasikan sebagai bahan inti deterjen.

\section{DAFTAR RUJUKAN}

Adiandri, R.S., 2006, Kajian Pengaruh Konsentrasi Metanol dan Lama Reaksi pada Proses Pemurnian Metil Ester Sulfonat terhadap Karakteristik Detergen Bubuk, Tesis, Fakultas Teknologi Pertanian IPB, Bogor.

Ardiyanto, K., 2012, Pembuatan dan Karakterisasi Deterjen dengan Bahan Aktif Surfaktan Etil Ester Sulfonat (EES) dari Minyak Biji Nyamplung (Calophyllum inophyllum L), Skripsi, Fakultas Sains dan Teknik MIPA UNSOED, Purwokerto.

Field, L. D., S. Sternhell, J. R. Kalman, 2007, Organic Structures from Spectra, Fourth Edition, John Wiley and Sons LTD, New York.

Haryani, K. dan Hargono, 2010, Pengaruh Jenis Solvent dan variasi Tray pada Pengambilan Minyak Nyamplung dengan Metode Ekstraksi Kolom, Prosiding Seminar Nasional Teknik Kimia "Kejuangan", UNDIP, Semarang.

Lewis, M. A., 1991, Chronic and Sublethal Toxicities of Sutfactants to Aquatic Animals, A Review and Risk Assessment. Wat. Res, 25(1), 101-113.

Mehling, A., M. Kleber, H. Hensen, 2007, Comparative Studies on the Ocular and Dermal Irritation Potential of Surfactants, Jurnal Food and Chem Toxicol, 14, 747758.

Sudarmadji, S., B. Haryono dan Suhardi, 1984, Prosedur Analisa Untuk Bahan Makanan dan Pertanian, Edisi Ketiga, Liberty, Yogyakarta.

Setyadi, M. dan Susianti, 2003, Studi Pembuatan Minyak Biodisel dari Minyak Biji Jarak, Prosiding Pertemuan dan Presentasi Ilmiah Penelitian Dasar Ilmu Pengetahuan dan Tenaga Nuklir, BATAN, Yogyakarta.

Sastrohamidjojo, H., 1992, Spektroskopi Inframerah, Liberty, Yogyakarta.

Silverstein, R. M., G. C. Bassler, T. C. Morril, 1981, Spectrometric Identification of Organic Compounds, Fourth Edition, John Wiley and Sons Inc., New York. 
Trimurti, B., C. Fauziah, dan Kristin, 2009, Aplikasi Enzim Protease dalam Formulasi Deterjen Cair Berbasis Metil Ester Sulfonat (MES) yang Ramah Lingkungan, Jurnal, Fakultas Teknologi Pertanian IPB, Bogor.

Utomo, R. N., 2010, Potensi Bakteri Pembentuk Biofilm dalam Mendegradasi Liniar Alkilbenzene Sulfonat pada berbagai Ukuran Batu, Skripsi, FMIPA Universitas Brawijaya, Malang.
Wuryaningsih, 2006, Kebutuhan akan Penggunaan Surfaktan di Indonesia, Puslit Kimia Lembaga Ilmu Pengetahuan Indonesia, Jakarta.

Yuninda, P., 2009, Kajian Pengaruh Suhu dan Lama Reaksi Sulfonasi pada Pembuatan Methyl Ester Sulfonic Acid (MESA) dari Metil Ester Minyak Biji Jarak Pagar (Jatropha Curcas L.) Menggunakan Single Tube Falling Reactor (STFR) Skala 5L, Skripsi, Fakultas Teknologi Pertanian IPB, Bogor. 